\title{
EL FACTOR HUMANO ENAVIACIÓN
}

TC. CAMILO BERNAL CERÓN.

Docente Especialización

en Gerencia de la

Seguridad Aérea - IMA n un medio netamente industrial como el
de la aviación, donde se mide la eficiencia
por horas voladas, con una tecnificación que presentó desarrollos inesperados en el siglo pasado, es difícil encuadrar al ser humano.

El ser humano no es medible, no es cuantificable en calidad, y sobre todo es imposible determinar su respuesta a determinadas situaciones. Sin embargo, el factor humano en este medio fue, es y sigue siendo el punto de quiebre en todos los procesos.

En la industria aeroespacial se conjugan diversos factores determinantes. Encontramos el de material, con todos los estudios sobre resisten-

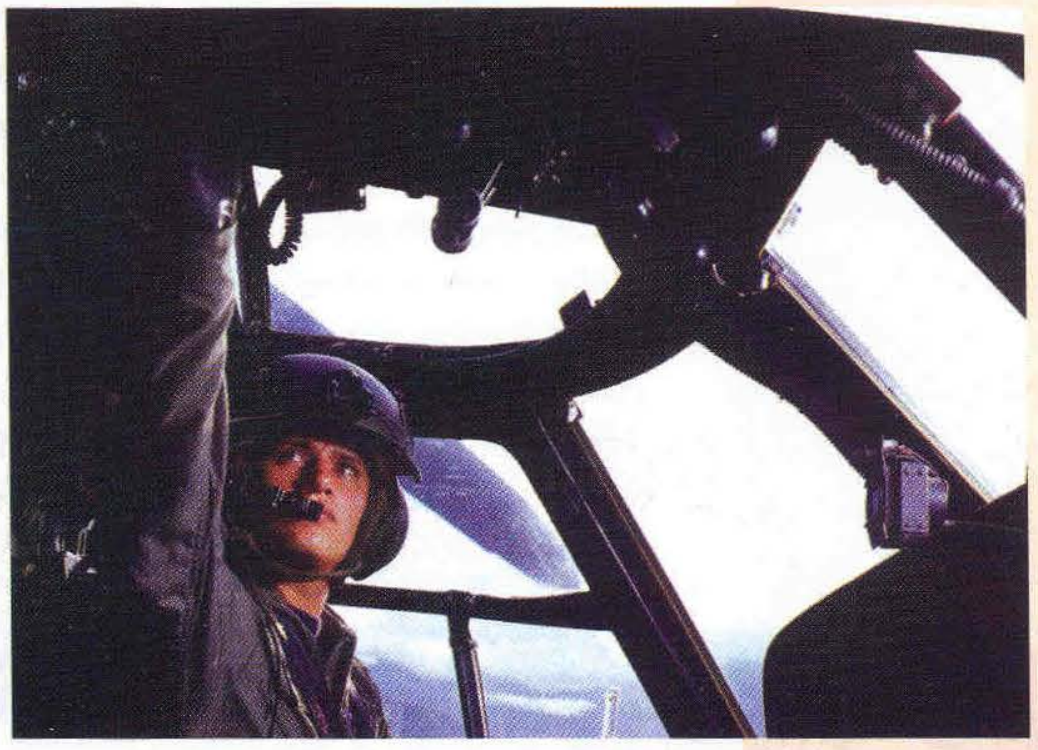
cias, aleaciones y propiedades; el factor diseño, involucrado en la disposición de los elementos tanto de cabina como del fuselaje, planos, plantas motrices, entre otros; y el no menos importante factor meteorológico, que ha causado mas de un dolor de cabeza, y así mismo el Factor Humano. Ese Factor Humano fue el que llevó al General George Paton a escribir: "Nunca le diga a las personas cómo hacer las cosas. Dígales qué hacer y ellos lo sorprenderán con su ingenio".

Ingenio que puede resolver problemas considerados imposibles de solucionar, como lo hicieron los hermanos Wright que construyeron en el año 1903, en su modesto taller de bicicletas, el primer aparato más pesado que el aire en volar por sus propios medios, solucionando el problema de control de vuelo mediante la observación del vuelo de las aves. Mientras que su más cercano competidor, el Coronel Langley, quien se encontraba auspiciado por el poderoso Instituto Smithsonian, a pesar de contar con un firme apoyo en recursos económicos y humanos, no pudo alcanzar la hazaña de los ingeniosos Wright.

Ese denominado Factor Humano es el puente del conocimiento que la fisiología y la psicología ha adquirido acerca del ser humano, el diseño y la ingeniería, todo dirigido al mejor funcionamiento de la mente-cuerpo del ser humano en la industria aeroespacial, aplicado tanto a las funciones de control de una aeronave como a lo relacionado con su funcionamiento, y en general a las operaciones aéreas cualquiera que sea su tipo.

La medicina continuamente se esfuerza por definir y entender las capacidades y limitaciones de los diferentes sistemas que componen el ser humano, entre ellos el cardiovascular, el nervioso o el osteomuscular, que a pesar de conformar un todo indivisible se ven influenciados así mismo por los sistemas de la aeronave como el de oxígeno, las fuerzas ocasionadas por las aceleraciones, el software y hardware de las cabinas, etc.

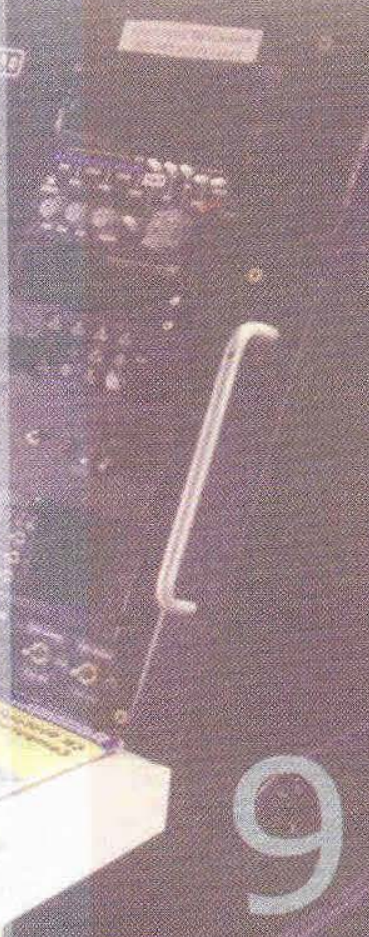


Dentro de los anteriores, el más complejo, impredecible y más difícil de estudiar es el sistema nervioso central en el hombre, y por lo tanto su mente y la capacidad de procesar información, de entenderla y reaccionar no pueden ser objeto de proyecciones consistentes.

Cada individuo de acuerdo a su pasado, cómo vive el presente y qué espera del futuro responde de una manera única a situaciones donde el factor humano es determinante para su solución. Es así como encontramos pilotos que en situaciones críticas ignoran alarmas visuales y auditivas a todas luces imposibles de no ver o escuchar, es cuando sobreviene un accidente y todo el andamiaje de la investigación de accidentes se enfrenta a su reto mayor: ¿Cómo diseñar los sistemas de la aeronave, de control aéreo o de mantenimiento a prueba de errores humanos?

Más aún, la pregunta podría ser: ¿Es posible evitar el error humano? Eugene Ionesco afirmaba "No es la respuesta lo que alumbra, sino la pregunta".

Esta pregunta nos lleva a un sinfín de respuestas. Una obvia es mejorar los sistemas tecnológicos de las cabinas, mejores computadores, mejores controladores de las variables del vuelo. Sin embargo surgen más preguntas, ¿si el desarrollo tecnológico ha avanzado tan vertiginosamente, por qué se siguen presentando errores por parte de las tripulaciones?. ¿Acaso la tecnología no le ofrece al piloto mejores herramientas para realizar sus vuelos con seguridad?

Al parecer, el error humano no depende tanto de la información que se presente, sino como se procese en el interior del cerebro del receptor. Por consiguiente el factor humano sigue siendo el paso obligado de la ruta de la investigación y prevención de accidentes.

Existen muchos ejemplos en el campo aeroespacial donde el entender el factor humano es crítico para el diseño y las habilidades necesarias para una determinada tarea. Es así como las exigencias físicas requeridas para ver, alcanzar, halar, empujar, hablar o activar controles mientras se lleva puesto un traje presurizado, guantes, casco, al tiempo que se está amarrado a una silla de eyección y se está sometido a aceleraciones de diverso tipo e intensidad deben ser claramente definidos.

Este estudio del Factor Humano es el que permite dar respuesta acertada y eficiente a las preguntas antes mencionadas.

Conocer el ser humano, desde sus partes al todo, permite identificar con algún grado de claridad las limitaciones que desde el punto de vista físico y mental puede presentar un tripulante.

Esto es válido en condiciones tanto de vuelo en la atmósfera terrestre como fuera de ella, en misiones como la conquista de Marte o la investigación en nuestro sistema solar.

Asegurarse de que el ser humano tiene la capacidad, tanto física como mental, de realizar actividades bajo condiciones asociadas con el espacio es la parte más importante del estudio de factores humanos en medicina aeroespacial.

Ahora es cuando el impulso y esfuerzo impreso al programa de Especialización en Seguridad Aérea en el área de factores humanos tiene su justificación.

Esto asegurará el éxito en la misión de preparar integralmente al Especialista en Seguridad Aérea, quien se enfrentará a uno de los retos más desafiantes en la industria aeroespacial, que influyó a los hermanos Wright y ahora influye en nosotros de la misma manera, el reto de entender el factor humano. 